\title{
Dikey Berkitmeli Alın Levhalı Kiriş-Kolon Birleşimlerin Davranışının Deneysel Olarak İncelenmesi
}

\author{
Investigation of Experimental Analysis on Behaviour of End-Plate Beam to Column \\ Connections with Vertical Stiffener
}

\author{
Mahyar MAALI* \\ Gençler Metal Çelik, Erzurum
}

• Geliş tarihi / Received: 16.12.2017 • Düzeltilerek geliş tarihi / Received in revised form: 14.02.2018 • Kabul tarihi / Accepted: 09.03.2018

$\ddot{O} z$

Kolon-kiriş birleşimleri yapı açısından oldukça önemlidir. Rijit veya mafsallı gibi basitleştirmeler yapılsa da, gerçek davranış farklıdır. Kolon kiriş birleşimlerin gerçek davranışı yarı rijit olarak tanımlanmaktadır. Yarı rijit birleşimlerin ana karakteristik özelliği doğrusal olmayan davranışıdır. Bu çalışmada düşey berkitmeli alın levhalı birleşimlerin moment dönme karakteristikleri deneysel olarak incelenmiştir. Önerilen metotta berkitmeler başlık ve gövdeye kaynaklanmıştır. Farklı alın levha kalınlıkları için önerilen birleşimin göçme şekilleri, moment-dönme eğrisi ve karakteristikleri karşılaş̧ırmalı olarak incelenmiştir. Ayrıca, bu birleşime yakın davranış gösteren ve aynı levha kalınlıklarına sahip kiriş gövdesine alın levhalı birleşimlerle önerilen tipteki birleşimlerin deney sonuçları karşılaştırmalı olarak değerlendirilmiş̧ir.

Anahtar kelimeler: Alın levhalı birleşim, Dikey berkitme, Kiriş-kolon birleşimi, Moment-dönme eğrisi, Yarı rijit birleşim

\begin{abstract}
The beam to column connections are very important for the structural point of view. However, the simplifications like rigid or hinged type joints, the real behavior and the idealized ones are different. The realistic behaviors of the beam to column connections are described as semi-rigid. The main characteristic of the semi-rigid connection is its nonlinear behavior. The moment rotation characteristics of the vertically stiffened end plate connections were investigated experimentally. The proposed method is to weld the stiffeners to the web and flange of the beam. The failure modes, the moment-rotation curves, and the characteristics were examined in comparison for variable end plate thickness. Moreover, the end plate connections, welded to web of the beam, with similar behavior, with same thickness, were investigated and compared with the proposed ones.
\end{abstract}

Keywords: End-plate connection, Vertical stiffener, Beam to column connection, Moment-rotation curve, Semi-rigid connection

*Mahyar MAALI; mahyar.maali@ gmail.com; Tel: (0534) 61501 63; orcid.org/0000-0002-6398-1139 


\section{Giriş}

Çerçeve sistemli çelik yapılarda kiriş-kolon birleşimleri yapı davranışında önemli rol oynamaktadır. Çelik yapıların tasarımında kullanılan hesap yöntemlerinin geliștirilmesinde yaklaşı 50 yıldır kiriş-kolon birleşimlerinin gerçek davranışı hem deneysel hem de teorik olarak araştırılmaktadır (Sağıroğlu ve Aydın, 2015).

Birleşimin gerçek davranışı olan yarı-rijit davranış, basit bir analiz ile kolaylıkla çözümlenemeyen ve doğrusal olmayan bir yapıya sahiptir. Günümüzde yaygın olarak kullanılan yarı-rijit birleşimler için dört ana veri bankası aşağıda kısaca sunulmuştur:

1- Goverdhan (1984) veri bankasi: Bu veri bankası 1950-1983 yılarında çeşitli araştırmacıların gerçekleştirdiği 230 adet birleşim için deney sonuçlarını düzenleyerek bir araya getirmiştir. Veri bankasının temelini oluşturan bu deneylerde, alın levhalı birleşim, alt ve üst başlık korniyerli birleşim, kiriş derinliğince alın levhalı birleşim, kısa alın levhalı birleşim, tek korniyerli gövde birleşim, alt ve üst başl1k korniyerli gövde çift korniyerli birleşim tipleri kullanılmıştır.

2- Nethercot (1985a, 1985b) veri bankası: Avrupada çelik elemanların birleşimleri için hazırlanmış bir veri bankasıdır. Nethercot, başka araştırmacıların incelediği (Jones vd., 1980) 700' ün üstünde bireysel çalışmayı derleyip tasnif ederek ele almıştır.

3- Çelik birleşimlerin veri bankası: Kishi ve Chen (Jones vd., 1980; Kishi ve Chen, 1986a; Kishi ve Chen, 1986b) ve Goverdhan (1985a) tarafindan temeli atılan bu veri bankası 1936' 1 yıllarda yapılmaya başlanmış 50 yıllık 303 deneyi içermektedir. Elde edilen bu veriler 1şı̆ğında oluşturulan matematik model ile deney sonuçları arasında bir ilişki kurulmaya çalışılmıştır. Abdalla ve Chen (1986) 46 adet deney ile bu veri tabanını 1955'te geliştirmişlerdir. $\mathrm{Bu}$ veri bankasının son halinde kiriş derinliğince alın levhalı birleşim, alın levhalı birleşim, alt ve üst başlık korniyerli gövde çift korniyerli birleşim, üst ve alt başlık korniyerli birleşim, kısa alın levhalı birleşim, tek korniyerli gövde birleşim ve çift korniyerli gövde birleşim tipleri ele alınmıştır.

4- SERICON veri bankasi: Aachen Üniversitesi ve Arbed Recherches ortaklığında kompozit birleşimler araştırılmıştır. Avrupa veri bankası olarak da nitelendirilebilecek bu deneyler daha sonra Cruz vd., (1998) tarafindan bu veri bankasını güncelleyerek SERICON II'yi olarak son halini ortaya çıkarmıştır.

Birleşimlerin sinıflandırmaları ve kurulan matematiksel modeller gerçek davranış1 yakalayabilmek maksadiyla geliştirilmiştir. Ancak, yaygın olarak kullanılan bu çalışmalarda birleşimler 7 grupta ele alınmıştır. Sınırlandırılmış bu yedi gruptaki birleşimler günümüzde kullanılan belirsiz bir yere sahiptir. Literatürde geçen bu 7 tip birleşim Şekil 1'de görselleştirilmiştir.

Ayrıca, birleşimlerin moment-dönme eğrilerinin modellenmesi üzerine yapılan çalışmalar, deneysel çalışmalar ile birlikte geliştirilmiştir ve 2000 yılından sonra yapılan deneyler ise aşağıda Tablo 1'de özetlenmiştir.

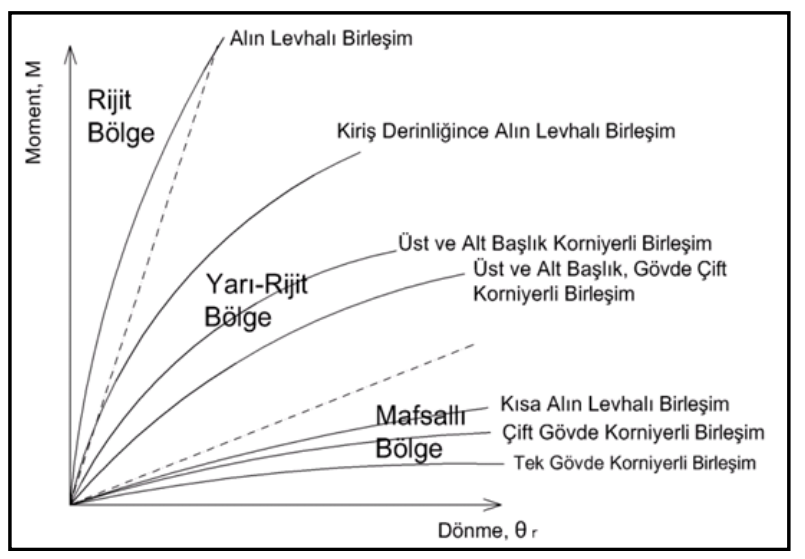

Şekil 1. Literatürde yaygın olarak görülen 7 tip birleşim için moment-dönme eğrileri

Bu çalışmada farklı dikey alın levhası kalınlığına sahip iki alın levhalı birleşim deneysel olarak ele alınmıştır. Kiriş başlığındaki berkitme levhalarının alın levhalı birleşimin davranışı üzerindeki etkisi incelenmiştir. Birleşim davranışı; moment-dönme eğrileri ile ifade edilmiş ve göçme modları değerlendirilmiştir. Sonuçlar birleşim bölgelerinin benzerliği ve levha kalınlıklarının aynı olması sebebiyle gerçekleştirilen deney sonuçları kiriş gövdesinde berkitmeli alın levhalı birleşim deney sonuçları (Sagiroglu, 2018) ile karşılaştırılmıştır.

\section{Deneysel Çalışma}

Bu çalışmada, Eurocode 3 (2005)'te yer alan ve uygulama rahatlığı dolayısıyla uygulamada sikça rastlanılan alın-levhalı birleşim tipi kullanılmıştır. 
Tablo 1. 2000 y1lı sonrasında yapılan birleşim deneyleri

\begin{tabular}{|c|c|c|}
\hline Çalışmalar & Açıklama & Deney sayısı \\
\hline Piluso ve Rizzano (2008) & Tekrarlı yük altında T birleşimler & 1 \\
\hline Coelho vd., (2009) & Eksenel yük altında alın levhalı plakalı birleşimler & 24 \\
\hline Abidelah vd., (2012) & $\begin{array}{l}\text { Eksenel yük altında berkitmeli ve berkitmesiz alın levhalı plakalı } \\
\text { birleşimler }\end{array}$ & 4 \\
\hline Aydın vd., (2015a) & Alt-üst korniyerli birleşimler & 9 \\
\hline Aydın vd., (2015b) & Alın levhalı sinus kiriş birleşimler & 4 \\
\hline Maali vd., (2016) & Alt-üst berkitmeli korniyerli birleşimler & 9 \\
\hline Maali vd., (2017) & Alt-üst korniyerli birleşimler & 10 \\
\hline
\end{tabular}

Literatürden farklı olarak alın levhaları iki ayrı alın levhalı ve üçgen levhalarla berkitmeli olarak tasarlanmıştır. Bu berkitmeler aynı zamanda alın levhalarına da kaynaklanmıştır. Deneylerde berkitme levhasının kalınlığ 1 sabit tutulurken alın levhaların kalınlığ 1 değiştirilmiştir. Çalışmaya esas teşkil eden deney modellerinin Şekil 2a'da geometrik özelikleri görülmektedir. Deney adları ve kullanılan birleşim elemanlarının boyutları Tablo 2'de sunulmuştur. Ayrıca, bu çalışma kapsamında yapılan deney sonuçları ile karşılaştırılan E160 ve E200 kodlu kiriş gövdesinde berkitmeli alın levhalı birleşimler Sağıroğlu'nun (2018) çalışmasından alınmış ve Şekil 2b'de sunulmuştur. Bu deneylerdeki E160 birleşimi IPE160 profilinden ve E200 birleşimi de IPE200 profilinden kesilerek elde edilen alın levhalı-elemanlarla oluşturulmuştur. Çalışma kapsamında incelenen levha kalınlıkları da bu birleşimlerle aynı olması için $7,4 \mathrm{~mm}$ ve $8,5 \mathrm{~mm}$ olacak şekilde seçilmiştir (IPE160 başlık kalınlığ 7,4 mm ve IPE200 levha kalınlığ 8,5 mm'dir).

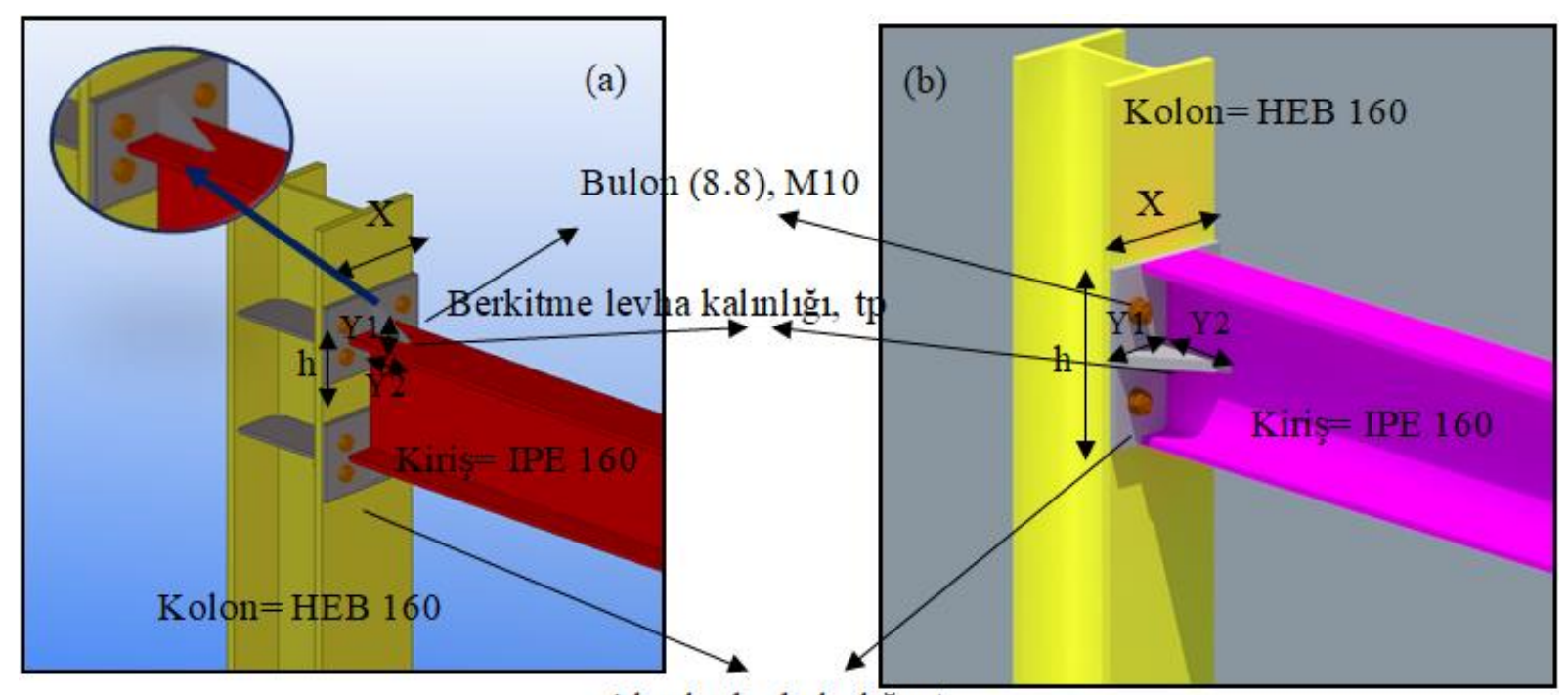

Alın levha kalınlığ $1, \mathrm{t}$

Şekil 2. Çalışmada kullanılan berkitmeli alın levhalı birleşim türleri. (a) Dikey berkitmeli alın levhalı birleşim. (b) Kiriş gövdesinde berkitmeli alın levhalı birleşim (Sağıroğlu, 2018).

Tablo 2. Deneylerde kullanılan birleşim elemanlarının boyutları

\begin{tabular}{lllllll}
\hline Deney Adı & $\mathrm{h}(\mathrm{mm})$ & $\mathrm{X}(\mathrm{mm})$ & $\mathrm{Y} 1(\mathrm{~mm})$ & $\mathrm{Y} 2(\mathrm{~mm})$ & $\mathrm{t}(\mathrm{mm})$ & $\mathrm{tp}(\mathrm{mm})$ \\
\hline V160 & 82 & 160 & 36 & 75 & 7.4 & 6 \\
V200 & 100 & 160 & 36 & 75 & 8.5 & 6 \\
E160 Sağıroğlu (2018) & 300 & 160 & 75 & 75 & 7.4 & 6 \\
E200 Sağıroğlu (2018) & 300 & 160 & 75 & 75 & 8.5 & 6 \\
\hline
\end{tabular}




\subsection{Deney Düzeneği ve Deneysel Verilerin Toplanmast}

$\mathrm{Bu}$ çalışma Atatürk Üniversitesi Mühendislik Fakültesi İnşaat Mühendisliği Bölümü Yap1 Laboratuvarında yapılmıştır. Deney düzeneğinde hidrolik pompa, yükleme hücresi (loadcell-250 $\mathrm{kN}$ ), deformasyon ölçüm cihazları (LVDTs-100 $\mathrm{mm}$ ), gerinim pulları (strain gauges), ve veri toplama cihazı (data logger) kullanılmıştır. Hidrolik pompa yükü yüklemek için kullanılmış ve yük hücresi, hidrolik pompaya bağlanmıştır. Gerinim pullarının kullanılacağı yer bu deneylerde önce yüzey taşlanıp zımparalanmış sonra aseton, eter gibi eriticilerle yüzey yağından temizlenmiştir. Gerinim pulları için yaygın kullanılan iki bileşenli yapıştırıcılar ölçüm yapılacak yere sürülmüştür. Deney numuneleri (kiriş-kolon birleşimleri) bir çelik inşaat (Gençler Metal Ltd. Şti.) firması yardımıyla hazırlanmıştır. Çalışmada amaç sadece kirişin eğilme davranışından birleşimin moment-dönme davranışı elde etmek olduğundan, kolonun muhtemel şekil değiştirmesini engellemek adına kolon boyutu büyük seçilmiştir. Birleşimde kullanılan kirişin burulmasını engellemek için ise kiriș ucuna iki kolonlu bir kılavuz bağlanmıș ve bu kolonlara mesafeleri ayarlanabilen kutu profiller monte edilmiştir. Deformasyon cihazlarını sisteme bağlamak için çerçeveli sistem imal edilmiştir. $\mathrm{Bu}$ sayede deformasyon ölçüm çihazları sabitlenmiş ve ölçüm hassasiyeti korunmuştur. Şekil 3 de deney düzeneği görülmektedir.

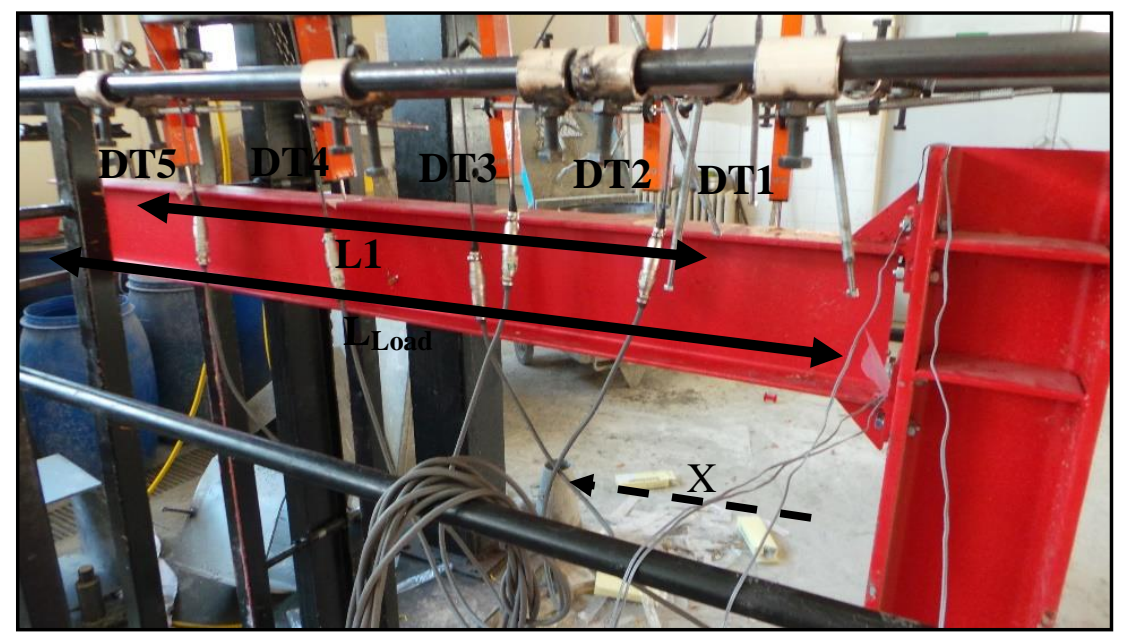

Şekil 3. Deney düzeneği

Burada L1 mesafesi DT1 ve DT5 arasındaki mesafe olarak adlandırılmıştır. Test edilen birleşimin davranışını ifade eden moment-dönme ilişkisi ve bu ilişkinin temsil ettiği moment dayanımı, rijitlik ve dönme kapasitesi verileri elde edilmiş, bu veriler eğrilerle görselleştirilmiştir ve sonuçlar tablo ile sunulmuştur. $\mathrm{Bu}$ çalışmada moment-dönme ilişkisinin söz konusu birleşimlerde nasıl değiştiği incelenmiştir. Ankastre mesnetli olarak tasarlanan deneylerde mesnetlerdeki moment aşağıdaki gibi hesaplanmıştır:

$\mathrm{M}=\mathrm{P} . \mathrm{L}_{\mathrm{load}}$

Burada; $P$, yük ve $\mathrm{L}_{\text {load, }}$ yükün uygulandığ 1 noktadan birleşim noktasına olan uzaklıktır. Birleşimdeki dönme Şekil 3'te görüldüğü gibi yatay ve dikey LVDT'lerle deplasmanlar ölçülerek aşağıdaki formüller ile hesaplanmıştır (Aydın vd., 2015b):

$\theta=\frac{\arctan \left(\delta_{D T 1}-\delta_{D T 5}-\left(\left(-\frac{P}{E I}\right)\left(\frac{X_{D T 1}^{3}}{6}-\frac{L_{l o a d} X_{D T 1}^{2}}{2}\right)\right)\right.}{L 1}$

Burada; I, kirişin atalet momenti ve E, elastisite modülüdür. $\Theta$, kirişin dönme değeri ve $\delta$, kirişin deplasmanıdır.

\section{Deney Sonuçları}

\subsection{Moment-Dönme Davranışı}

Şekil 4'te görülen moment-dönme eğrisi ile eğilme momenti $\left(\mathrm{M}_{\mathrm{j} . \mathrm{Rd}}\right)$ ve dönme $\left(\Theta_{\mathrm{j} . \mathrm{Rd}}\right)$; maksimum moment $\left(\mathbf{M}_{\mathrm{j} . \max }\right)$ ve bu maksimum momente karş1lık gelen dönme $\left(\Theta_{\text {Mj.max }}\right)$; ve eğilme moment kapasitesi $\left(\mathrm{M}_{\ominus . \mathrm{Cd}}\right)$ ile eğilme 
moment kapasitesindeki dönme $\left(\Theta_{\mathrm{cd}}\right)$ arasındaki ilişki açıklamaktadır (Eurocode 3, 2005).

Tablo 2'de tanımlanan gerçek ölçekli iki deney gerçekleştirilmiş ve Şekil 5'te bu deneyler için önerilen birleşimlerin moment-dönme eğrileri karşılaştırmalı olarak verilmiştir. Tablo 3'te bu deneylere ait moment-dönme eğrilerinin karakteristik değerleri ve Şekil 6'da ise önerilen birleşimler ile kiriş gövdesinde berkitmeli alın levhalı birleşimlerin moment-dönme eğrileri karşılaştırılmıştır.

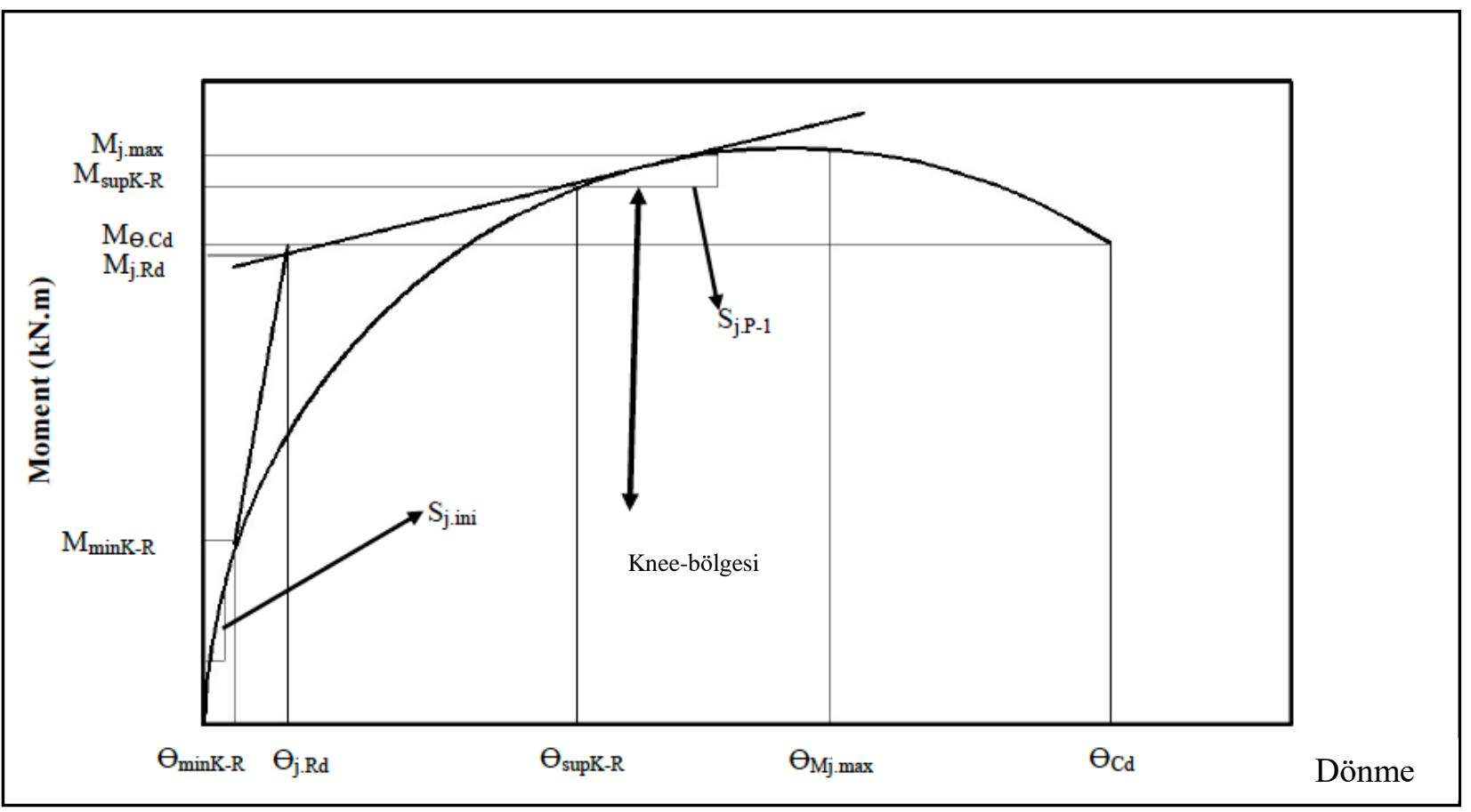

Şekil 4. Moment-dönme eğrisi karakteristikleri (Aydın vd., 2015a,b; Maali vd., 2016; Maali vd., 2017).

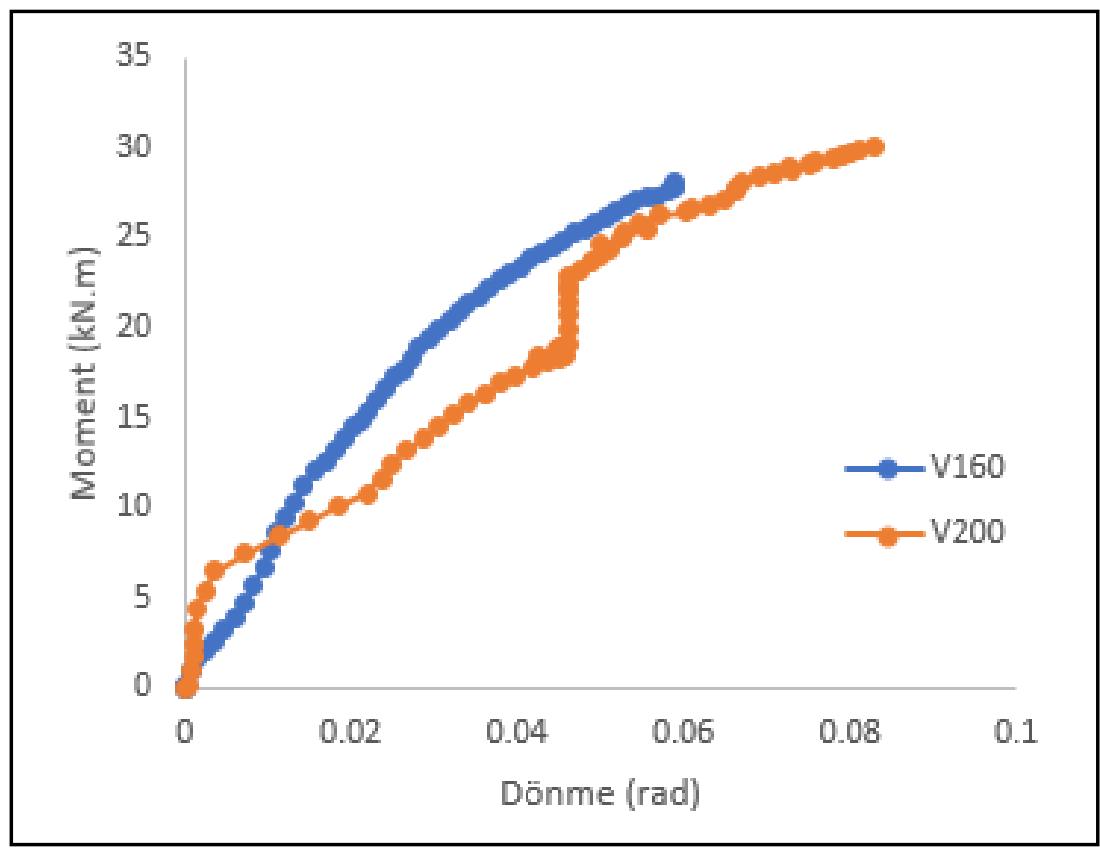

Şekil 5. V160 ve V200 birleşimlerinin moment-dönme eğrileri 
Tablo 3. Moment-dönme eğrisi karakteristik değerleri

\begin{tabular}{|c|c|c|c|c|c|}
\hline Deney Ad 1 & & V160 & V200 & E160 Sağıroğlu (2018) & E200 Sağıroğlu (2018) \\
\hline \multirow{3}{*}{ Dayanım (KNm) } & $\mathrm{M}_{\mathrm{j} . \mathrm{Rd}}$ & 18.87 & 18.50 & 13.81 & 10.82 \\
\hline & $\mathrm{M}_{\mathrm{j} \text { max }}$ & 28.06 & 30.07 & 15.42 & 14.44 \\
\hline & $\mathrm{M}_{\Theta \mathrm{Cd}}$ & 28.06 & 30.07 & 14.91 & 14.44 \\
\hline \multirow{3}{*}{ Rijitlik (KN m/rad) } & $S_{\mathrm{j} . \mathrm{ini}}$ & 1.05 & 2.69 & 6.91 & 2.81 \\
\hline & $S j_{. p-1}$ & 0.32 & 0.21 & 0.099 & 0.16 \\
\hline & $S_{j . \text { inin }} / S_{j . p-1}$ & 3.23 & 12.64 & 9.13 & 17.11 \\
\hline \multirow{3}{*}{ Dönme $\quad$ (rad) } & $\overline{\Theta_{j . R d}}$ & 0.025 & 0.007 & 0.037 & 0.016 \\
\hline & $\Theta_{\text {Mj.max }}$ & 0.059 & 0.083 & 0.077 & 0.118 \\
\hline & $\Theta_{\mathrm{Cd}}$ & 0.059 & 0.083 & 0.085 & 0.119 \\
\hline$\Psi_{\mathrm{j}}$ & & 2.36 & 11.86 & 2.29 & 7.44 \\
\hline$\Psi_{\mathrm{j} . \max \text { load }}$ & & 2.36 & 11.86 & 2.08 & 7.38 \\
\hline $\begin{array}{l}\text { Enerji Yutma kapasitesi } \\
\text { (kNmrad) }\end{array}$ & & 0.83 & 1.25 & 0.63 & 0.86 \\
\hline
\end{tabular}

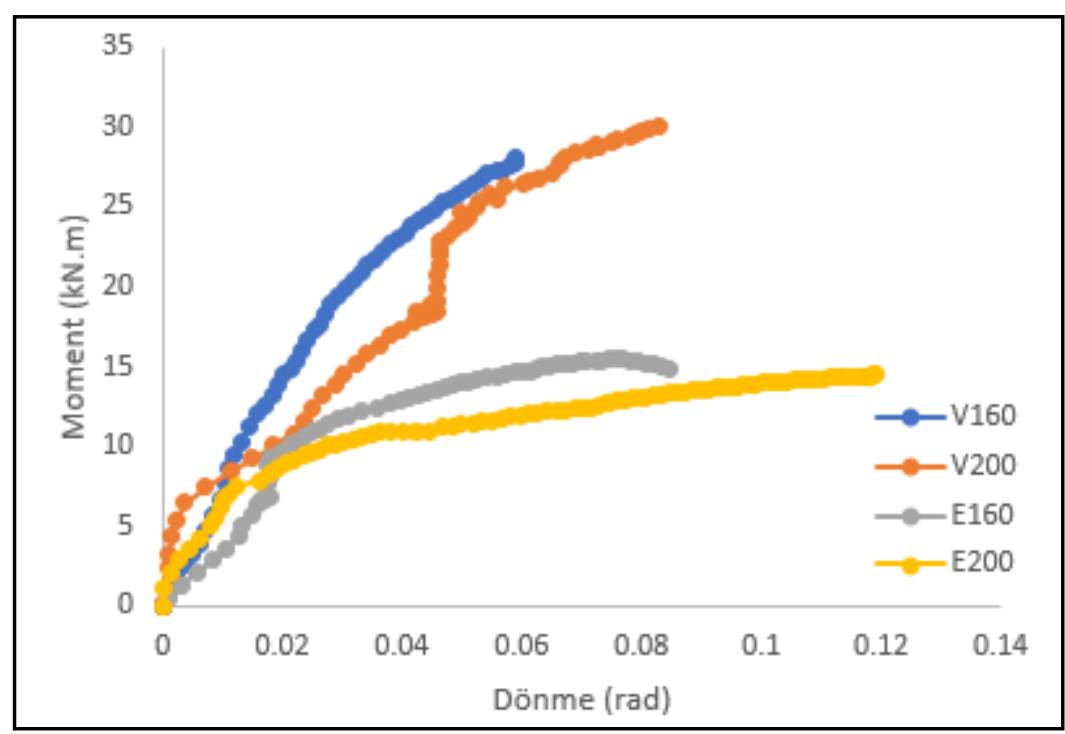

Şekil 6. V160, V200, E160 ve E200 birleşimlerinin moment-dönme eğrileri

Bu çalışma kapsamında yapılan V160 ve V200 deneyleri için Tablo 3'te görüldüğü gibi birleşimlerin alın levhası kalınlığı arttıç̧a süneklik ve maksimum sünekliğin $\% 502.54\left((11.86 / 2.36)^{*} 100\right)$ ve enerji yutma kapasitesinin \%150.60 ((1.25/0.83)*100) arttı̆g1 görülmektedir. Deney numunelerinin dayanımları birbirleriyle karşılaştırıldığında, alın levhasının kalınlığ1 arttıça $\mathrm{M}_{\mathrm{jRd}} \quad$ nin \%98.04 $\left((18.5 / 18.87)^{*} 100\right)$ oranında azaldı $\breve{g} 1, \quad \mathrm{M}_{\mathrm{jmax}}$ ve $\mathrm{M}_{\ominus c d} \operatorname{nin} \% 107,16((30.07 / 18.87) * 100)$ oranında artığ1 görülmüştür. Sonuç olarak alın levha kalınlığ1 arttıkça dayanım oranının arttığ1 anlaşılmaktadır. Elastik bölgedeki nihai rijitlik $\left(\mathrm{S}_{\mathrm{j} . \mathrm{ini}}\right) \% 256.19$ olarak artaken, plastik bölgedeki rijitlik ise \%65.63 oranında azalmıştır. Ayrıca elastik bölgedeki nihai rijitliğin plastik bölgedeki rijitliğe oran1 $\left(\mathrm{S}_{\mathrm{j} . \mathrm{ini}} / \mathrm{S}_{\mathrm{j} \text {.p-1 }}\right)$ ise \%391.33 artmıştır. Dönme oranları ise, alın levhasının kalınlığı arttıkça $\Theta_{\text {Mj.max }}$ ve $\Theta_{\mathrm{Cd}}$ 'da \%140.68 artmıştır. Ancak, ilgili deneylerde bulon kesmesi meydana geldiği göz önünde bulundurulmalıdır. Sonuç olarak, alın levhasının kalınlığının artması moment dayanımını ve dönme kapasitesini artırmıştır.

$\mathrm{Bu}$ sonuçlar, literatürdeki kiriş gövdesinde berkitmeli alın levhalı birleşimlerin sonuçları ile karşılaştırıldığında (Sagiroglu, 2018); V160 ve E160 ile V200 ve E200 için sirasıyla maksimum moment ve kritik moment \%181.97 ve \%208.24 artarken, maksimum dönme ve kritik dönmenin $\% 76.62$ ve $\% 70.34$ azaldığ görülmektedir. Yine sırasıyla rijitlik \%35.37 ve \%73.91 azalmıştır. 
Süneklik $\left(\Psi \mathrm{j}=\frac{\theta C d}{\theta M R d}\right)$ ve maksimum süneklik $\left(\Psi \mathrm{j}_{\text {maxload }}=\frac{\Theta M j \cdot \max }{\Theta M R d}\right) \quad \% 103.05 \quad$ ve $\% 159.41$ oranında artmıştır. Enerji yutma kapasitesi ise \%131.74 ve \%145.35 oranında artmıştır. Böylece, dikey alın levhalı birleşimlerde kiriş gövdesinde berkitmeli alın levhası kullanımı, birleşimi rijitleştirmiş, moment dayanımını artırmış ve dönmeyi azaltmıştır.

\subsection{Göçme Şekilleri}

Eurocode 3'te alın levhalı birleşimlere ilişkin üç çeşit göçme tipi mevcuttur (Eurocode 3,2005). Şekil 7'de Eurocode 32'te verilen göçme tipleri sunulmaktadır. Şekil 7a 'da sadece akma, Şekil 7b 'de akma ve bulon kırılması ve Şekil 7c 'de ise sadece bulon kırılması söz konusudur. V160 ve V200 birleşimlerinin her ikisinde de göçme 4 adet üst bulon kırılması ile meydana gelmiştir. Ayrıca, Şekil 8'de görüldüğg̈ gibi üst alın levhası, kullanılan berkitme levhasının etkisiyle V şeklini alarak deforme olmuştur. Ayrıca, alt alın levhasında farklı bir göçme şekli meydana gelmemiştir. E160 ve E200 birleşimlerinin her ikisinde de göçme üst bulon kırılması ile meydana gelmiş̧ir. Söz konusu iki tip alın levhalı birleşim deneylerinde Şekil 7b'de görülen göçme modu ortaya çıkmıştır.

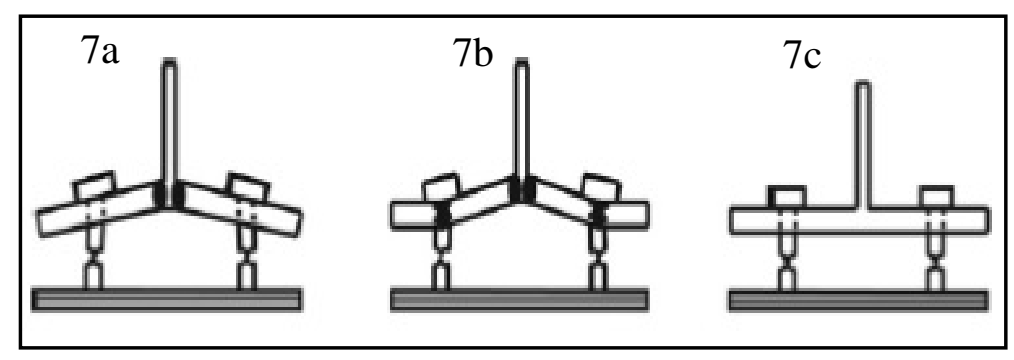

Şekil 7. Eurocode göçme modları (EN1993-1-8, Eurocode 8: Design of steel structures-Parts 1-8: General Rules-Design of joints, CEN, 2005).

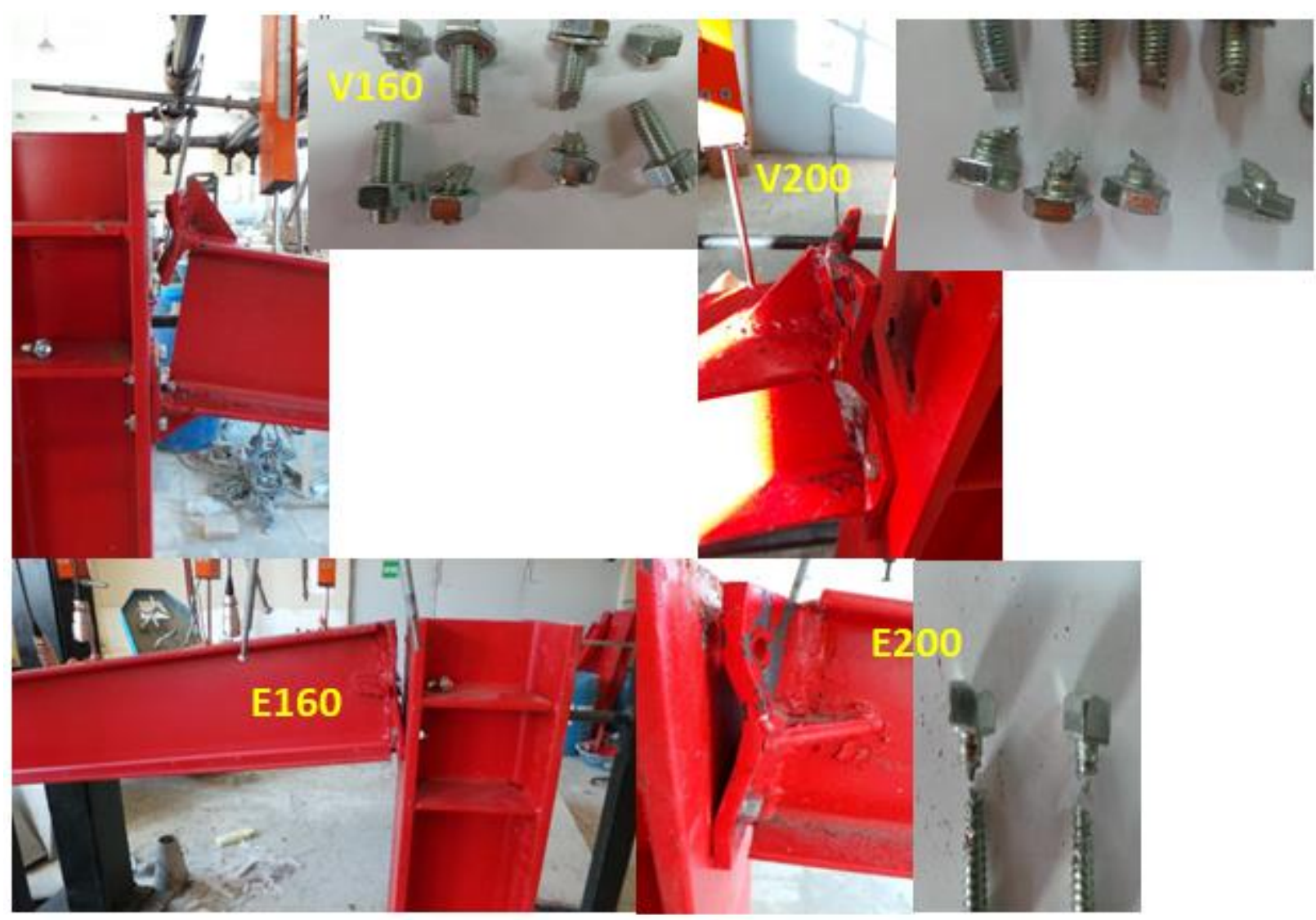

Şekil 8. Deneylerin göçme modları. 


\section{Sonuç}

$\mathrm{Bu}$ çalışmada, önerilen dikey alın levhalı birleşimin davranışını temsil eden moment-dönme eğrisinin belirlenmesi adına bir deneysel çalışma gerçekleştirilmiştir. Yapılan deneyler göstermiştir ki, birleşimin moment-dönme eğrisi birleşim elemanının boyutlarına göre değişmektedir. Buna bağlı olarak birleşimin eleman boyutlarındaki farklılığın moment-dönme eğrisinin temsil ettiği rijitlik, moment dayanımı, süneklik ve enerji yutma kapasitesi ve ne ölçüde değiştirdiği ile ilgili bilgi edinilmektedir. Bu çalışma kapsamında, alın levhası kalınlığı arttıkça süneklik ve maksimum süneklilik ve enerji yutma kapasitesi artmıştır. Deney numunelerinin dayanımları birbirleriyle karşılaştırıldığında, alın levha kalınlığı arttıkça dayanım oranının artığı görülmüştür. Ayrıca alın levhasının kalınlığı arttıkça rijitlik artmıştır. Bu deney sonuçları, kiriş gövdesinde berkitmeli alın levhalı birleşim deney sonuçları ile karşılaştırıldığında (Sağıroğlu, 2018); V160 ve E160 ile V200 ve E200 için sırasıyla maksimum moment ve kritik moment artarken, maksimum dönme ve kritik dönme azalmıştır. Böylece, kiriş gövdesinde berkitmeli alın levhalı olarak kullanılan birleşimlerin sünekliği daha az, enerji yutma kapasitesinin ise arttığı anlaşılmıştır. Böylece, moment dayanımı artarken dönme azalmıştır.

Çelik yapı şantiyelerinde ve/veya fabrikalarında artık profil, levha ve lama parçaları sıkça bulunmaktadır. Alın levhalı bir birleşim yapılması durumunda elde mevcut çelik parçalarından hazırlanacak çalışmaya esas olan küçük üçgen berkitmelerin ilgili birleşimlerde kullanılması artık malzemelerin değerlendirilmesi hususunda etkin bir yöntem olarak öne çıkmaktadır. Ayrıca tasarımı gerçekleştirilen birleşimin enerji yutma kapasitesinde sağlandığı artış ile muhtemel deprem performansının da iyileşeceği ön görülmektedir. $\mathrm{Bu}$ çalışmada sunulan üçgen berkitmeli alın levhalı birleşimlerin ve muhtemel alternatiflerinin deneysel ve sayısal olarak gerek monotonik gerek se dinamik ve tekrarlı yükler altında davranışlarının değerlendirilmesi geleceğe matuf öneriler olarak değerlendirilebilir.

\section{Kaynaklar}

Abdalla, K.M. ve Chen, W.F., 1995. Expanded database of semi-rigid steel connections. Computers \& Structures, 56(4), 553-64.

Abidelah, A., Bouchaï, A. ve Kerdal, D.E., 2012. Experimental and analytical behavior of bolted end-plate connections with or without stiffeners. Journal of Constructional Steel Research, 76, 13-27.

Aydın, A.C., Maali, M., Kılıç, M. ve Sagiroglu, M., 2015a. Experimental Investigation of Sinus Beams with End-Plate Connections. Thin-Walled Structures, 97, 35-43.

Aydın, A.C., Kılıç, M., Maali, M. ve Sagiroglu, M., 2015b. Experimental Assessment of the Semi-Rigid Connections Behavior with Angles and Stiffeners. Journal of Constructional Steel Research, 114, 338348.

Coelho, A.M.G., Bijlaard, F.S.K. ve Kolstein, H., 2009. Experimental behaviour of highstrength steel web shear panels. Engineering Structures, 31(7), 1543-55.

Cruz, P.J.S., Simões, d.S., Rodrigues, D.S. ve Simões, R.A.D., 1998. SERICON IIdatabase for the semi-rigid behaviour of beam-to-column connections in seismic regions. Journal of Constructional Steel Research, 46(1-3), 233-234.

EN1993-1-8, 2005. Eurocode 8: Design of steel structures-Parts 1-8: General Rules-Design of joints. CEN.

Goverdhan, A.V., 1984. A collection of experimental moment-rotation curves and valuation of prediction equations for semirigid connections. Master thesis. Nashville (TN), Vanderbilt University.

Jones, S.W., Kirby, P.A. ve Nethercot, D.A., 1980. Effect of semi-rigid connections on steel column strength. Journal of Construtional Steel Research, 1, 38-46.

Kishi, N. ve Chen, W.F., 1986a. Steel connection data bank program, In: Structural engineering, 2nd ed, School of Civil Engineering, Purdue University, West Lafayette, Report no. CE-STR86-18.

Kishi, N. ve Chen, W.P., 1986b. Data base of steel beam-to-column connections, In: Structural engineering., School of Civil Engineering, Purdue University, West Lafayette, 1/2, Report no. CE-STR-86-26.

Maali, M., Kılıç, M. ve Aydın, A.C., 2016. Experimental Model of the Behaviour of 
Bolted Angles Connections with Stiffeners. Int. Journal of Steel Structures, 16(3), 1-15.

Maali, M., Kılıç, M., Sagiroglu, M. ve Aydın, A.C.; 2017. Experimental Model for Predicting the Semi-Rigid Connections' Behaviour with Angles and Stiffeners. Advances in Structural Engineering, 20, 6, 884-895.

Nethercot, D.A., 1985a. Steel beam-to-column connections: a review of test data and its applicability to the evaluation of joint behaviour in the performance of steel frames. CIRIA report, 338.

Nethercot, D.A., 1985b. Utilization of experimentally obtained connection data in assessing the performance of steel frames (Editör : Chen WF). Connection flexibility and steel frames, Proc. of a Session Sponsored by the ASCE Structural Division, Detroit.

Piluso, V. ve Rizzano, G., 2008. Experimental analysis and modelling of bolted T-stubs under cyclic loads. Journal of Constructional Steel Research, 64(6), 655669.

Sagiroglu, M., 2018. Kiriş gövdesinde berkitmeli alın levhalı birleşimlerin davranışının deneysel analizi. Sakarya Üniversitesi Fen Bilimleri Enstitüsü Dergisi, no: 310649.

Sağıroğlu, M. ve Aydın, A.C., 2015. Design and analysis of non-linear space frames with semi-rigid connections. Steel and Composite Structures, 18, 6, 1405-1421. 